\title{
THE OCTOBER MEETING IN WORCESTER
}

The five hundred seventy-second meeting of the American Mathematical Society was held at the College of the Holy Cross on October 22, 1960. 100 people registered, including 68 members of the Society.

Professor Shreeram Abhyankar of the Johns Hopkins University and Harvard University addressed the Society on the subject Introduction to Analytic Geometry, by invitation of the Committee to Select Hour Speakers for Eastern Sectional Meetings. Professor N. H. McCoy introduced the speaker.

There were two sessions for contributed papers. The presiding officers were Professors W. E. Hartnett and J. S. Stubbe.

Abstracts of contributed papers appear in the Notices for October (issue number 48) and later issues.

Everetr Pitcher, Associate Secretary 